\title{
Psychiatry
}

\section{Yoga can Give Blissful Life}

\author{
Vijay Mohan Soni and Neha Munjal*
}

Lovely Professional University, Punjab, India

Correspondence should be addressed to Neha Munjal, neha.18869@lpu.co.in

Received: April 26, 2021; Accepted: May 4, 2021; Published Date: May 11, 2021

\section{LETTER TO EDITOR}

"The purification of the mind is very necessary."

- Sri S. Satchidananda, The Yoga Sutras

Yoga is currently flourishing worldwide. In the Indian culture, Yoga is considered as a pathway towards attainment of joy in life, freedom from sorrows, mental balance and peace. In the current situation of pandemic, there is a need of well-being of both physical and mental health. Yoga is the only solution for the attainment of this. The regular practice of Yoga can help to improve health strengthen the immunity. Yogic practices help to improve blood circulation, metabolism, reproductive disorder, respiratory disorders, cardiovascular diseases, diabetes etc. Yoga is widely popular for treatment of chronic health conditions. But there are mental health benefits also it can replace traditional psychotherapy. It improves the mental and emotional resilience. This helps the people to fight with anxiety, stress, and depression and ultimately gives mental well-being. Since ancient times, the seekers of selfrealization (often called as Rishis or Yogis) have been practicing yoga for balancing the mind and body for attaining spiritual realization. The various terminologies have been used such as Nirvana, Moksha, Atmasakshaatkar etc., all having the same notion i.e. liberation from suffering. Sage Patanjali, said that the main purpose of the Yoga is the regulation of mind. Even in Bhagvad Gita, the yoga is elaborated as the tool get relief from sorrows of life [1-3].

योगस्थ: कुरू कर्माणि संगं त्यक्त्वा धनंजय:।

सिद्ध्यसिद्धयो: समो भूत्वा समत्वं योग उच्यते।।

There are several types of yoga being described such as Hatha yoga-Physical Yoga, Gyan Yoga - Knowledge Yoga, Bhakti Yoga- Emotional Yoga, Raj Yoga-Mental Yoga, Laya yoga-Meditation Yoga. Yogic practices include posture (Asana), breathe regulation (Pranayama), introspection (Pratyahar), contemplation (Dharana) and meditation (Dhyan) and union with divine (samadhi).

"संयोग योग इत्युक्तो जीवात्मपरमात्मनो।".

Yoga has a huge potential for mental health. Yoga can help the individuals' to take positive charge of their own psychological wellness. Yoga can be introduced as a new therapy for curative, preventive, protective measures for mental well-being.

In the war against COVID-19, the daily practice of Yoga can play the vital role for healthy well-being.

Citation: Vijay Mohan Soni, Yoga can Give Blissful Life. Psychiatry 1(2): 29-30.

(C) 2021 The Authors. Published by TRIDHA Scholars. 
http://www.tridhascholars.org | December-2021

\section{योगश्चित्तवृत्तिनिरोधः ॥२ ॥}

Yogaścittavṛttinirodhaḥ \|2\|

"Yoga (yogah) is the suppression (nirodhah) of the modifications (vṛtti) of mind (citta) $\| 2 \mid "$ ".

\section{REFERENCES}

1. https://patanjaliyogasutra.in/

2. https://bhagavad-gita.org/

3. https://www.ayush.gov.in/ 